\title{
Lim-3 Durumundaki 4. Mertebe Operatörlerin Dissipatif Genişlemeleri
}

\author{
Hüseyin TUNA ${ }^{1, *}$ \\ ${ }^{1}$ Mehmet Akif Ersoy Üniversitesi, Fen Edebiyat Fakültesi, Matematik Bölümü, Burdur
}

Özet

Bu çalışmada, Lim-3 durumundaki skaler 4. mertebeden difereasiyel operatörlerinin maksimal dissipatif, kendine eş ve diğer genişlemeleri verilmiştir.

Anahtar Kelimeler: Dissipatif genişlemeler, kendine eş genişlemeler, sınır değer uzayı, sınır koşulu

\section{Dissipative Extensions of Fourth Order Differential Operators in the Lim -3 Case ${ }^{2}$}

Abstract

In this article, we give a description of all maximal dissipative, self adjoint and other extensions of scalar fourth order differential operators in the lim 3 case.

Keywords: Dissipative extensions, self adjoint extensions, a boundary value space, boundary condition

*e-mail: hustuna@gmail.com

${ }^{2}$ This work was presented in "International Conference on Analysis and Applied Mathematics", Gümüşhane/TURKEY, on 18-21 October 2012 and only the abstract of this work was published in the "Abstract Book" of the "International Conference on Analysis and Applied Mathematics". 
Tuna H.

\section{Introduction}

The theory of extensions of symmetric operators developed orginally by J. Von Neumann [1]. The problem on the description of all self adjoint extensions of a symmetric operator in terms of abstract boundary conditions was put forward for the first time in Calkin [2]. Later, Rofe- Beketov [3] described self adjoint extensions of a symmetric operator in terms of abstract boundary conditions with aid of linear relations. Bruk [4] and Kochubei [5] are introduced the notion of a space of boundary values. They described all maximal dissipative, acretive, self adjoint extensions of symmetric operators. For a more comprehensive discussion of extension theory of symmetric operators, the reader is referred to [6].

A description of self adjoint extensions of a second order operator on an infinite interval was obtained by Fulton [7] and Krein [8]. For a scalar fourth order equation and two term differential expressions of arbitrary even order, the same question was investigated by Khol'kin [9], Mirzoev [10]. Gorbachuk [11] obtained a description of self adjoint extensions of Sturm Liouville operators with an operator potential in the absolutely indeterminate case. In the case when the deficiency indices take indeterminate values, a description of self adjoint extensions of differential operators was given in the works of Allahverdiev [12], Guseinov and Pashaev [13], Maksudov and Allahverdiev [14], Malamud and Mogilevsky [15], Mogilevsky [16].

In this paper, a space of boundary value is constructed for scalar fourth order differential operators in the Lim-3 case. We describe all maximal dissipative, acretive, self adjoint and other extensions in terms of boundary conditions.

\section{Extensions of Fourth Order Differential Operators in the Lim-3 Case}

Let us consider the differential expression

$$
1(y)=y^{(4)}+q(x) y, 0 \leq x<+\infty,
$$

where $\mathrm{q}(\mathrm{x})$ is a real continuous function in $[0, \infty)$.

We denote by $\mathrm{L}_{0}$ the closure of the minimal operator (see [17]) generated by (2.1) and by $\mathrm{D}_{0}$ its domain. Further, we denote by the set of all functions $y(x)$ from $L_{2}(0, \infty)$ whose first three derivatives are locally absolutely continuous in $[0, \infty)$ and $\mathrm{l}(\mathrm{y}) \in \mathrm{L}_{2}(0, \infty)$; $\mathrm{D}$ is the domain of the maximal operator $\mathrm{L}$, and $\mathrm{L}=\boldsymbol{L}_{\boldsymbol{o}}^{*}($ see [17]).

Assume that $\mathrm{q}(\mathrm{x})$ be such that the operator $\mathrm{L}_{0}$ has defect index $(3,3)$. Let $\mathrm{v}_{1}(\mathrm{x}), \mathrm{v}_{2}(\mathrm{x}), \mathrm{v}_{3}(\mathrm{x})$ denote the solutions of $1(y)=0$ satisfying the initial conditions

$$
\begin{aligned}
& \mathrm{v}_{1}(0)=1, \mathrm{v}_{1}{ }^{\prime}(0)=0, \mathrm{v}_{1}{ }^{\prime \prime}(0)=0, \mathrm{v}_{1}{ }^{\prime \prime \prime}(0)=0, \\
& \mathrm{v}_{2}(0)=0, \mathrm{v}_{2}{ }^{\prime}(0)=1, \mathrm{v}_{2}{ }^{\prime \prime}(0)=0, \mathrm{v}_{2}{ }^{\prime \prime \prime}(0)=0, \\
& \mathrm{v}_{3}(0)=0, \mathrm{v}_{3}{ }^{\prime}(0)=0, \mathrm{v}_{3}{ }^{\prime \prime}(0)=1, \mathrm{v}_{3}{ }^{\prime \prime \prime}(0)=0,
\end{aligned}
$$

$\mathrm{v}_{1}(\mathrm{x}), \mathrm{v}_{2}(\mathrm{x}), \mathrm{v}_{3}(\mathrm{x})$ are linearly independent and their Wronskian equals one. Since $\mathrm{L}_{0}$ has defect index $(3,3), \mathrm{v}_{1}(\mathrm{x}), \mathrm{v}_{2}(\mathrm{x}), \mathrm{v}_{3}(\mathrm{x}) \in \mathrm{L}_{2}(0, \infty)$.

We denote by $\Gamma_{1}, \Gamma_{2}$ the linear maps from $\mathrm{D}$ to $\mathrm{C}^{3}$ defined by the formula

$$
\boldsymbol{\Gamma}_{1} \boldsymbol{f}=\left(\begin{array}{c}
\boldsymbol{f}(\mathbf{0}) \\
\boldsymbol{f}^{\prime}(\mathbf{0}) \\
{\left[\boldsymbol{f}, \boldsymbol{v}_{3}\right]_{\infty}}
\end{array}\right), \boldsymbol{\Gamma}_{2} \boldsymbol{f}=\left(\begin{array}{c}
\boldsymbol{f}^{\prime \prime \prime}(\mathbf{0}) \\
\boldsymbol{f}^{\prime \prime}(\mathbf{0}) \\
{\left[\boldsymbol{f}, \boldsymbol{v}_{2}\right]_{\infty}}
\end{array}\right),(2.2)
$$

where 
$[y, z]_{x}=\left[y^{\prime \prime \prime}(\mathrm{x}) \mathrm{z}(\mathrm{x})-\mathrm{y}(\mathrm{x}) \mathrm{z}^{\prime \prime \prime}(\mathrm{x})\right]-\left[\mathrm{y}^{\prime \prime}(\mathrm{x}) \mathrm{z}^{\prime}(\mathrm{x})-\mathrm{y}^{\prime}(\mathrm{x}) \mathrm{z}^{\prime \prime}(\mathrm{x})\right](0 \leq \mathrm{x}<\infty)$.

Lemma 1. For arbitrary $y, z \in D$

$$
(\boldsymbol{L} \boldsymbol{y}, \boldsymbol{z})_{\mathrm{L}^{2}}-(\boldsymbol{y}, \boldsymbol{L z})_{\mathrm{L}^{2}}=\left(\boldsymbol{\Gamma}_{1} \boldsymbol{y}, \boldsymbol{\Gamma}_{2} \boldsymbol{z}\right)_{\mathrm{C}^{3}}-\left(\boldsymbol{\Gamma}_{2} \boldsymbol{y}, \boldsymbol{\Gamma}_{1} \boldsymbol{z}\right)_{\mathrm{C}^{3}} \cdot
$$

Proof. For every y,z $\in$ D we have Green's formula

$$
(\boldsymbol{L} y, z)_{\mathrm{L}^{2}}-(\boldsymbol{y}, \boldsymbol{L z})_{\mathrm{L}^{2}}=[\boldsymbol{y}, \bar{z}]_{\infty}-[\boldsymbol{y}, \bar{z}]_{0} .
$$

Then

$\left(\boldsymbol{\Gamma}_{1} \boldsymbol{y}, \boldsymbol{\Gamma}_{2} \boldsymbol{z}\right)_{\mathrm{C}^{3}}-\left(\boldsymbol{\Gamma}_{2} \boldsymbol{y}, \boldsymbol{\Gamma}_{1} \boldsymbol{z}\right)_{\mathbf{C}^{3}}=\mathrm{y}(0) \mathrm{z}^{\prime \prime \prime}(0)-\mathrm{z}(0) \mathrm{y}^{\prime \prime \prime}(0)+\mathrm{y}^{\prime \prime}(0) \mathrm{z}^{\prime}(0)-\mathrm{z}^{\prime \prime}(0) \mathrm{y}^{\prime}(0)+\left[\boldsymbol{y}, \boldsymbol{v}_{2}\right]_{\infty}\left[\overline{\boldsymbol{z}}, \boldsymbol{v}_{3}\right]_{\infty} \quad-\left[\overline{\boldsymbol{z}}, \boldsymbol{v}_{2}\right]_{\infty}$ $\left[\boldsymbol{y}, \boldsymbol{v}_{3}\right]_{\infty}$.

We know that every $y, z \in D$

$$
\left[\boldsymbol{y}, \boldsymbol{v}_{2}\right]_{\infty}\left[\overline{\mathbf{z}}, \boldsymbol{v}_{3}\right]_{\infty}-\left[\overline{\mathbf{z}}, \boldsymbol{v}_{2}\right]_{\infty}\left[\mathbf{y}, \mathbf{v}_{3}\right]_{\infty}=[\boldsymbol{y}, \overline{\mathbf{z}}]_{\infty}(\text { see }[9]) .
$$

Hence

$$
\left(\boldsymbol{\Gamma}_{1} \boldsymbol{y}, \boldsymbol{\Gamma}_{2} z\right)_{\mathrm{C}^{3}}-\left(\boldsymbol{\Gamma}_{2} \boldsymbol{y}, \boldsymbol{\Gamma}_{1} \boldsymbol{z}\right)_{\mathrm{C}^{3}}=[\boldsymbol{y}, \bar{z}]_{\infty}-[\boldsymbol{y}, \bar{z}]_{0}
$$

Then we have

$$
(\boldsymbol{L} \boldsymbol{y}, \boldsymbol{z})_{\mathrm{L}^{2}}-(\boldsymbol{y}, \boldsymbol{L z})_{\mathbf{L}^{2}}=\left(\boldsymbol{\Gamma}_{1} \boldsymbol{y}, \boldsymbol{\Gamma}_{2} \boldsymbol{z}\right)_{\mathbf{C}^{3}}-\left(\boldsymbol{\Gamma}_{2} \boldsymbol{y}, \boldsymbol{\Gamma}_{1} \boldsymbol{z}\right)_{\mathrm{C}^{3}}
$$

Lemma 2. For any complex numbers $\alpha_{0}, \alpha_{1}, \alpha_{2}, \alpha_{3}, \beta_{0}, \beta_{1}$, there is a function $y \in D$ satisfying

$$
\begin{gathered}
\mathrm{y}(0)=\alpha_{0}, \mathrm{y}^{\prime}(0)=\alpha_{1}, \mathrm{y}^{\prime \prime}(0)=\alpha_{2}, \mathrm{y}^{\prime \prime \prime}(0)=\alpha_{3},(2.3) \\
{\left[\boldsymbol{y}, \boldsymbol{v}_{2}\right]_{\infty}=\beta_{0},\left[\boldsymbol{y}, \boldsymbol{v}_{3}\right]_{\infty}=\beta_{1} .}
\end{gathered}
$$

Proof. Let $\mathrm{f}$ be an arbitrary element of $\mathrm{L}_{2}(0, \infty)$ satisfying

$$
\left(\boldsymbol{f}, \boldsymbol{v}_{2}\right)_{\mathbf{L}^{2}}=\beta_{0}+\alpha_{2},\left(\boldsymbol{f}, \boldsymbol{v}_{3}\right)_{\mathbf{L}^{2}}=\beta_{1}-\alpha_{1} .(2.4)
$$

There is such an $\mathrm{f}$, even among the linear combinations of $\mathrm{v}_{1}, \mathrm{v}_{2}$, and $\mathrm{v}_{3}$. If we set $\mathrm{f}=\mathrm{c}_{1} \mathrm{v}_{1}+\mathrm{c}_{2} \mathrm{v}_{2}+\mathrm{c}_{3} \mathrm{v}_{3}$ then conditions (2.4) are a system of equations in the constants $c_{1}, c_{2}, c_{3}$ whose determinant is the Gram determinant of the linearly independent functions $\mathrm{v}_{1}, \mathrm{v}_{2}, \mathrm{v}_{3}$ and is therefore nonzero. Let $\mathrm{y}(\mathrm{x})$ denote the soulution of $1(y)=f$ satisfying the initial conditions $y(0)=\alpha_{0}, y^{\prime}(0)=\alpha_{1}, y^{\prime \prime}(0)=\alpha_{2}, y^{\prime \prime \prime}(0)=\alpha_{3}$. We claim that $\mathrm{y}(\mathrm{x})$ is the desired element. Applying Green' formula to $\mathrm{y}(\mathrm{x})$ and $\boldsymbol{v}_{\boldsymbol{j}}$ we obtain

$$
\left(f, v_{j}\right)_{\mathrm{L}^{2}}=\left(l(y), v_{j}\right)_{\mathrm{L}^{2}}=\left[y, v_{j}\right]_{\infty}-\left[y, v_{j}\right]_{0}, \mathrm{j}=2,3 .
$$

But $1\left(\boldsymbol{v}_{\boldsymbol{j}}\right)=0(\mathrm{j}=2,3)$. Since $\mathrm{y}(0)=\alpha_{0}, \mathrm{y}^{\prime}(0)=\alpha_{1}, \mathrm{y}^{\prime \prime}(0)=\alpha_{2}, \mathrm{y}^{\prime \prime \prime}(0)=\alpha_{3}$, we have

$$
\left[y, v_{j}\right]_{0}=\left\{\begin{array}{c}
-\alpha_{2}, j=2 \text { ise } \\
\alpha_{1}, j=3 \text { ise }
\end{array}\right.
$$

Therefore,

$$
\begin{aligned}
& \left(\boldsymbol{f}, \boldsymbol{v}_{2}\right)_{\mathrm{L}^{2}}=\left[\boldsymbol{y}, \boldsymbol{v}_{2}\right]_{\infty}+\alpha_{2}, \\
& \left(\boldsymbol{f}, \boldsymbol{v}_{3}\right)_{\mathrm{L}^{2}}=\left[\mathbf{y}, \mathbf{v}_{3}\right]_{\infty}-\alpha_{1} .
\end{aligned}
$$

Hence and from the conditions (2.4), we have

$$
\left[\boldsymbol{y}, \boldsymbol{v}_{2}\right]_{\infty}=\beta_{0},\left[\boldsymbol{y}, \boldsymbol{v}_{3}\right]_{\infty}=\beta_{1} .
$$

We recall that a triple $\left(\mathrm{H}, \Gamma_{1}, \Gamma_{2}\right)$ is called a space of boundary values of a closed symmetric operator A on a Hilbert space $\mathrm{H}$ if $\Gamma_{1}$ and $\Gamma_{2}$ are linear maps from $\mathrm{D}\left(\boldsymbol{A}^{*}\right)$ to $\mathrm{H}$ with equal deficiency numbers and such that:

i) for every f, $g \in \mathrm{D}\left(\boldsymbol{A}^{*}\right)$,

$$
\left(\boldsymbol{A}^{*} \mathbf{f}, \mathbf{g}\right)_{\boldsymbol{H}^{-}}\left(\mathbf{f}, \boldsymbol{A}^{*} \mathbf{g}\right)_{\boldsymbol{H}}=\left(\boldsymbol{\Gamma}_{1} \boldsymbol{f}, \boldsymbol{\Gamma}_{2} \boldsymbol{g}\right)_{\boldsymbol{H}^{-}}\left(\boldsymbol{\Gamma}_{2} \boldsymbol{f}, \boldsymbol{\Gamma}_{1} \boldsymbol{g}\right)_{\boldsymbol{H}} ;
$$

$$
\text { any } \mathrm{F}_{1}, \mathrm{~F}_{2} \in \mathrm{H} \text { there is a vector } \mathrm{f} \in \mathrm{D}\left(\boldsymbol{A}^{*}\right) \text { such that } \Gamma_{1} \mathrm{f}=\mathrm{F}_{1}, \Gamma_{2} \mathrm{f}=\mathrm{F}_{2}([5],[18]) \text {. }
$$


Theorem 1. The triple $\left(\mathrm{C}^{3}, \Gamma_{1}, \Gamma_{2}\right)$ defined by (2.2) is a boundary spaces of the operator $\mathrm{L}_{0}$.

Proof. First condition of the definition of a space of boundary value follows from Lemma 1 and second condition follows from Lemma 2.

Corollary 1. For any contraction $K$ in $C^{3}$ the restriction of the operator $L$ to the set of functions $y \in D$ satisfying either

$$
(\mathrm{K}-\mathrm{I}) \Gamma_{1} \mathrm{y}+\mathrm{i}(\mathrm{K}+\mathrm{I}) \Gamma_{2} \mathrm{y}=0(2.5)
$$

or

$$
(\mathrm{K}-\mathrm{I}) \Gamma_{1} \mathrm{y}-\mathrm{i}(\mathrm{K}+\mathrm{I}) \Gamma_{2} \mathrm{y}=0(2.6)
$$

is respectively the maximal dissipative and accretive extension of the operator $\mathrm{L}_{0}$. Conversely, every maximal dissipative (accretive) extension of the operator $\mathrm{L}_{0}$ is the restriction of $\mathrm{L}$ to the set of functions $y \in D$ satisfying (2.5) ( (2.6) ), and the contraction $\mathrm{K}$ is uniquely determined by the extension. The maximal symmetric extensions of $\mathrm{L}_{0}$ in $\mathrm{L}_{2}(0, \infty)$ are described by conditions (2.5) ( (2.6) ), in which $\mathrm{K}$ is an isometry. These conditions define selfadjoint extensions if $\mathrm{K}$ is unitary.

\section{References}

[1] Von Neumann J., "Allgemeine Eigenwertheorie Hermitischer Functionaloperatoren", Math. Ann. 102,49-131, 1929.

[2] Calkin J. W., “Abstract boundary conditions”, Trans. Amer. Math. Soc.,45, 3, 369-442, 1939.

[3] Rofe-Beketov F.S., "Self-adjoint extensions of differential operators in a space of vector valued functions"”, Dokl. Akad. Nauk SSSR 184,1034-1037, 1969 ; English transl. in Soviet Math. Dokl. 10,188-192, 1969.

[4] Bruk V. M. "On a class of boundary --value problemswith a spectral parameter in the boundary conditions”, Mat. Sb., 100, 210-216. , 1976.

[5] Kochubei A. N., "Extensions of symmetric operators and symmetric binary relations", Mat. Zametki 17, 41-48, 1975; English transl. in Math. Notes 17, 25-28, 1975.

[6] Gorbachuk M.L., "Gorbachuk V.I. and Kochubei A.N., The theory of extensions of symmetric operators and boundary-value problems for differential equations", Ukrain. Mat. Zh. 4112991312, 1989; English transl. in Ukrainian Math. J. 41, 1117-1129, 1989.

[7] Fulton C.T., "Parametrization of Titchmarsh"s $m(\lambda)$ - functions in the limit circle case", Trans. Amer. Math. Soc. 229, 51-63, 1977.

[8] Krein M. G., "On the indeterminate case of the Sturm-Liouville boundaryvalue problem in the interval $(0, \infty) "$, Akad. Nauk SSSR Ser. Mat. 16, 292-324, 1952.

[9] Khol'kin A. M., "Self-adjoint boundary conditions at-infinity for a quasi regular system of evenorder differential equations", 174-183 in: Theory of operators in function spaces and its applications, Naukova Dumka, Kiev, 1981.

[10] Mirzoev G. A., "Fourth order quasi regular differential operator" Dokl. Akad. Nauk SSSR 251, no.3, 550-553, 1980; English transl. Soviet Math. Dpkl. 21, 480-483, 1980. 
[11] Gorbachuk M. L., "On spectral functions of a second order differential operator with operator coefficients”, Ukrain. Mat. Zh. 18, no.2, 3-21, 1966; English transl. Amer. Math. Soc. Transl. Ser. II 72, 177-202, 1968.

[12] Allahverdiev B. P., "On extensions of symmetric Schrödinger operators with a matrix potential”, Izvest. Ross. Akad. Nauk. Ser . Math. 59, 19-54, 1995; English transl. Izv. Math. 59, 45-62, 1995.

[13] Guseĭnov I. M. and Pashaev R. T., "Description of self adjoint extensions of a class of differential operators of order $2 \mathrm{n}$ with defect indices $(\mathrm{n}+\mathrm{k}, \mathrm{n}+\mathrm{k}), 0<\mathrm{k}<\mathrm{n}$ ", Izv.Akad.Nauk Azerb. Ser. Fiz. Tekh. Mat. Nauk, No.2, 15-19 (in Russian), 1983.

[14] Maksudov F.G. and Allahverdiev B.P., "On the extensions of Schrödinger operators with a matrix potentials", Dokl. Akad. Nauk 332, no.118-20, 1993,;English transl. Russian Acad. Sci. Dokl. Math. 48 no.2, 240-243, 1994.

[15] Malamud M. M. and Mogilevskiy V. I., "On extensions of dual pairs of operators, Dopov". Nats Akad. Nauk. Ukr. no. 1, 30-37, 1997.

[16] Mogilevskiy V. I., "On proper extensions of a singular differential operator in a space of vector functions”, Dopov. Akad. Nauk. Ukraini, no.9, 29-33 (in Russian) , 1994.

[17] Naimark M. A., "Linear Differential Operators", 2nd edn.,1968, Nauka, Moscow, English transl. of 1st. edn., 1,2, New York, 1969.

[18] Gorbachuk M. L. and Gorbachuk V. I., "Boundary Value Problems for Operator Differential Equations”, Naukova Dumka, Kiev, 1984; English transl., Birkhauser Verlag 1991. 